Boise State University

ScholarWorks

Communication Faculty Publications and

Presentations

Department of Communication

$8-1-2010$

\title{
COMMUNEcation: A Rhizomatic Tale of Participatory Technology, Postcoloniality and Professional Community
}

Kirsten J. Broadfoot

Colorado State University

Debashish Munshi

University of Waikato

Natalie Nelson-Marsh

Boise State University 


\title{
COMMUNEcation: A Rhizomatic Tale of Participatory Technology, Postcoloniality and Professional Community
}

\author{
Kirsten J. Broadfoot \\ Colorado State University, USA \\ Debashish Munshi \\ University of Waikato, New Zealand \\ Natalie Nelson-Marsh \\ Boise State University, USA
}

Keywords: culture, community, conferencing, diversity, participation, postcolonial, technology, web 2.0

\begin{abstract}
This article explores our experiences in creating and participating with(in) a virtual conference organized as an experimental virtual network. These experiences demonstrate how physically co-located and virtual conferencing practices acting in tandem provide a greater opportunity for the inclusion of both diverse perspectives and participants in professional community. Using insights from postcolonial theory, we examine how the architecture of participation found in the technologies of Web 2.0 accentuates the potential for reclaiming some diversity of perspective and participation, facilitating a form of molecular community through conferencing practices. Finally, we provide theoretical and empirical insights and reflections on the social dynamics of conferencing in both online and offline spaces to demonstrate how online conferencing can expand the directions taken in pursuit of new collective knowledge.
\end{abstract}

\section{Introduction}

The concept of 'cultural technologies' as 'assemblages of technology, content, context, power relations, and social knowledge' (Flew, 2005: 26) encompasses the symbiotic relationship between technology and culture. Technologies 'facilitate communication through which culture is constructed' (Green, 2001: 23). Construction of such cultures across time and space has been well documented by scholars (see e.g., Kreiner and Schultz, 1995; Nelson-Marsh, 2007; Rheingold, 2003). Yet, not as much attention has been paid to how cultural technologies can help re-configure colonialist notions of space into hybrid spheres of interaction, where the real and the virtual cohabit to build 'inter-local' (Simpson, 2008) linkages that nurture local identities and coconstruct syncretic identities and alternative global partnerships. As cultural studies scholars such as Beck and Lau (2005) argue, the new age of Web 2.0 blurs global/local boundaries and it is in the blurring of the boundaries that we can see a 'meshing of technology, society, and culture' (Flew, 2005: 28) and a potential nurturing of reflexivity 'at the interface of the social and the technical' (Lash, 2003: 55).

In this article, we focus our attention on a hybrid sphere of interaction - a virtual conference and community of scholars based in five different continents and with diverse disciplinary backgrounds. Moving away from a colonialist mindset of territorial boundaries emphasized by the obsession with cartography and visions of the world from privileged vantage points (Shohat \& Stam, 1996), we examine this hybrid space from a postcolonial perspective. Such a postcolonial approach, Shohat \& Stam argue, resists constructed notions of national borders, ‘stresses deterritorialization' (1996: 38) and 'addresses complex, multi-layered identities ... generated by the geographical displacements characteristic of the post-independence era' (1996: 41). Drawing on these commitments and concepts of cosmopedia and the architecture of deterritorialization from Pierre Lévy (1997), we re-conceptualize what it means to act 'locally' and yet simultaneously be part of a 'professional community' through the interweaving of real-life associations and individually-crafted material texts on the one hand and online conversations among scholars with no prior connections and co-constructed texts on the other. We use as a case study, our experiences of COMMUNEcation, a virtual conference organized as an experimental virtual network to demonstrate how physically co-located and online/virtual conferencing practices acting in tandem provide a greater opportunity for the inclusion of both diverse perspectives and participants rather than just participating in one form or the other. COMMUNEcation also demonstrates the degree to which structuring practices can be flexed in order to negotiate and value diversity, legitimacy, authority and knowledge at the same time. 
In the sections that follow, we examine, using insights from postcolonial theory and the work on collective intelligence by Lévy, the social, ecological and corporate contours of academic conferences, specifically the ways in which the communicative structuring of scholarly conferencing acts to restrain and constrain diversity and community within the academic diaspora. We then present our experiences in organizing and participating in COMMUNEcation, an international online academic conference and community using the participatory technologies of Web 2.0, and discuss its potential for reclaiming some diversity in the espoused goals of scholarly and professional conferencing and community. Finally, we provide theoretical and empirical insights and reflections on the social dynamics of conferencing in both online and offline spaces to demonstrate how online conferencing can expand the directions taken in pursuit of new collective knowledge. To put this hybrid space in context, let us first look at the spatial, and consequentially political, cultural, and ideological boundaries around traditional face-to-face professional conferences.

\section{Problematizing the Privileged Culture Of Conferencing}

As scholars and professionals, we aim to advance knowledge about human interaction in organizational settings. We ask questions, conduct research, theoretically interpret findings, and make claims about how people interact, why they interact as they do, and what significant implications such interaction might have. To challenge and advance knowledge of human interaction, we enlist and engage other scholars in dialogue about our research, and use conferences as forums for these meta-dialogues. Yet, surprisingly, we do not often question or critique the taken-for-granted assumptions about the nature, structure, and prefecture of these conferences and their practices. Why do scholars and other professionals conference? What do they accomplish through such practices? How do they conference and how can this activity be done differently to not just include multiple geographically dispersed and economically disadvantaged others, but to facilitate a fluid, non-hierarchical, dimension of multiplicity?

Traditional face-to-face conferencing is a privileged activity. It is a practice requiring funding, travel, and time away from home. Its current restrictive structures involving issues of time, place, and cost, and constrictive processes such as scheduling, formats of panels, and respondents demarcate who can and cannot be present. These current restrictive structures and constrictive processes act as exclusionary mechanisms to reduce diversity in conferencing content, practices, presences, and voices. The consequence of such exclusions, we argue, is a seriously limited scholarly and professional understanding and experience of the wider community as well as contemporary social relations.

Although conferences are beneficial in that they serve as spaces for scholarly and professional exchange, traditional conferences are at best platforms for what Deleuze and Guattari might call 'arborescent multiplicities' (2004: 36). Such platforms, diverse as they may be in a variety of senses, are characterized by an 'organization of territoriality' and a ‘one-way hierarchy' (Deleuze and Guattari, 2004:37). The communicative and organizing processes involved in such an 'organization of territoriality' can often lead to scholarly disenchantment, as discussed below by a junior professional in our own discipline:

'While the respondent for a panel I presented on at the ... [conference] this year was quite good and offered very useful feedback, in general respondents ... are not that helpful, from what I witnessed in other panels. Respondents make a lot of "fluffy" comments rather than blend the right amount of facesaving praise with sharp, constructive criticism. [The Association] seems, based on my first experience, to be light on the whole "developing scholarship" thing and heavy on the greasy, political networking stuff. As an academic conference, it feels like a fraternity mixer ... I do recognize the value of all the many lines of communication scholarship coming together, and I suppose [the Association] is the venue for that. But the expense for a monstrous conference is ridiculous. I propose a remedy for this: a virtual conference. (Posting in a listserv, 2006).

Recognizing the presence of such frustrations amongst community members, a recent survey of conference participants at a large communication conference asked scholars why they conference - to keep up with recent research, meet and socialize with colleagues and friends, and improve their academic record. But as the posting cited above suggests, these goals are not always met and even when they are met, it is met only for a particular few. Indeed, the assumption that professional conferencing is necessary for both the pursuit of knowledge and career advancement has directly contributed to growing numbers in professional association membership and conference attendance in the past. One would think that the large number of participants would contribute to a greater diversity in conference participation. However, this does not appear to be the case. In fact, with the increase in the size of conferences comes a variety of problems that actually threaten to decrease the diversity of voices that contribute to the conversation and knowledge production about human interaction. 
One central problem involves the cost of attending multi-day conferences. Major academic conventions like other professional conferences, are economically, socially and politically restrictive for diverse participants. Contractual obligations that professional organizations enter into with participating venues and hotels constrain participants in their choices of accommodation and travel. Individuals with care commitments also find it difficult to participate in conferences due to the multi-day format. Many international participants face the additional burden of organizing visas, which are especially tedious, time-consuming, and emotionallydebilitating for those from countries that are seen to be on the 'other' side of geo-political divides. The issue of time is no less important. Dates chosen to suit the academic calendar in the U.S., for example, are not necessarily convenient for scholars based in other parts of the world.

These issues prompt us to problematize professional conferencing in three ways. First, we propose that it is problematic to argue that only one form of embodied participation counts in professional dialogue and community. If we conceptualize 'presence' as a form of professional collaboration or kinship that transcends boundaries of time, space, and, more importantly, narrowly-defined codes of practice, we radically alter the nature of and need for 'conferences' as we currently understand them as geographically and temporally bounded entities. Indeed, 'conferencing' in the definitional sense, already occurs through various taken-for-granted means enabling interconnection and perpetuating interdependence among nationally and internationally distributed colleagues. Scholars and professionals distributed across various spans of space and time collaborate as they prepare to submit, present, and participate in formalized, geographically and temporally bounded 'conferences'. This raises an interesting question: If we are already 'conferencing' across time and space before the 'conference', why do participants actually need to meet face to face at a physically-located 'conference'? Conferencing is, of course, essential to what Wenger (1999: 237) calls 'communities of practice', providing an infrastructure of engagement that helps individuals learn as they participate in the activities of a social or professional group. Moreover, shared identities emerge from these engaged community relationships through the 'physical (and virtual) spaces; interactive technologies and communication facilities that extend mutual access in time and space' (1999: 237). It seems possible, therefore, to reproduce various conferencing patterns of practice such as participating in panels, commenting, and questioning content without being physically present while simultaneously affirming the symbolic assumption that participating in this dialogue enhances knowledge about life-worlds. Such a re-conceptualization of conferencing as a dynamic and deterritorialized practice that dissolves boundaries between particular forms of knowledge and specializations to allow members to compose and decompose identity and knowledge in a reciprocal manner and in a interactive, often multimediated representational space, draws heavily on Lévy’s notion of ‘cosmopedia’ (1997: 214-217).

Second, and building on the above point, if conferencing occurs through taken-for-granted practices that enable interaction and the organization of thought, it is also possible to imagine a conference as disorganization, as a 'virtual realm of creative processes and becomings' (Pearson, 1999, cited in Clegg, Kornberger, and Rhodes, 2005: 159) and a form of organizational learning 'that allows for creative invention' (Clegg, Kornberger, and Rhodes, 2005: 149). Conceptualized in this way, conferencing becomes central to creating, constructing and connecting the professional diaspora and community. Such a focus on the process of 'becoming' paves the way for understanding conferences as organizations, collectives or communities in a perpetual state of flux and flow, 'a form of dis-organization that connects with and can destabilize the desire for a unified, timeless and static idea of organization', to unearth the ways in which taken-for-granted practices lead to a silencing of diverse voices (Clegg et. al, 2005: 161). A re-conceptualization of conferencing as a form of 'molecular community' (Lévy, 1997: 53) begins to emerge now as our scholarly attentions shift to the ways in which participants 'communicate laterally, reciprocally, outside categories and hierarchies, folding and refolding, weaving and reweaving’ (Lévy, 1997: 53).

A final problematic involves the inability of so many unseen participants from geographically dispersed regions to physically attend conferences which excludes them from the conversations held there, stifling the diversity of voices at these meetings, and creating a knowledge base shaped by dominant perspectives. From a postcolonial perspective, this knowledge base perpetuates a division between institutional elites and colonized others (Broadfoot \& Munshi, 2007). So how can scholars as professionals question and critique the restrictive and constrictive nature of current conferencing practices that act to exclude others? Should scholars and their voices, confronted by these challenges, be rendered silent and therefore illegitimate due to their lack of participation? Finally, how can we begin to engage an 'architecture of deterritorialization' (Lévy, 1997: 127) to develop diverse social bonds as well as the forms of apprenticeship and exchanges of knowledge that occur at traditional forms of conferences?

Such questions, inspired by Raka Shome's (1996) call to reflect on the extent to which organizing and communicative practices in academe may legitimize hegemonic power structures, prompt us to begin to imagine a more inclusive form of conferencing and to make room in our minds for alternative, postcolonially inspired 
ways of communicating and organizing. In this essay, we explore the degree to which online or virtual conferencing may provide an alternative organizing structure that can open up 'rhizomatic multiplicities' (Deleuze \& Guattari, 2004: 37) through facilitating networks 'in which communication runs from any neighbour to any other, the stems or channels do not pre-exist, ... and the final, global result is synchronized without central agency' (Deleuze \& Guattari, 2004: 19). Such a structure challenges the arborescent structure of an organizational tree and its inherently hierarchical trunk and branches found in traditional academic and professional conferences and communities.

\section{New Technologies, New Media, New Organizing}

Traditional technologies and forms of media involved with conferencing reinforce the boundaries of 'space' marked by physical venues of presentations and face-to-face sessions; 'time' denoted by the specified dates and times of these sessions; and 'text' encoded in the asynchronous and analogous abstracts and full papers. However, contemporary technological tools and the medium of the internet provide 'a mechanism for widelydispersed individuals to interact with one another' as part of distributed communities (Gochenour, 2006: 34). Indeed, such communities give us a chance to see 'how individuals function in a polyvalent way outside of specific spaces' (Gochenour, 2006: 34). This is not to say that technology necessarily paves the ground for diversity to flourish. As several scholars in the area of the sociology of technology (see e.g., Poster, 1995; Markley, 1996; Gajjala \& Mamidipuni, 2002; McKibben, 2003) assert, mere technological connectivity does not always equate to equity. Moreover, new technologies and media are not value-neutral (see e.g., Munshi et. al, 2007) and can potentially lead to what Bagchi, Sinha, and Bagchi call a 'cognitive imperialism' (2005: 10) if users other than from the Western world remain a 'passive observer and recipient' (Bagchi, Sinha, \& Bagchi, 2005:10).

A postcolonial approach to technology and new media however, recognizes the constructed meaning of these technological tools and harnesses specific forms that allow individuals in diverse locations to be active participants in framing new organizational processes and cultures. Indeed, when we imagine professionals and conferencing as flows of activity, part human and part technological, part real and part virtual, part material and part philosophical, we begin to create a different cultural 'space' which both pushes and crosses boundaries of nations, institutions, disciplines, and even languages. Such a postcolonially inspired imagining does not argue that the use of technology or new media is an end in itself. Nor does it argue that technology and new media are magic wands capable of ushering in equity and diversity to professional worlds. But it does attempt to find an alternative and complex architecture of reconfigured organizations in which those who are shut out of the rigid enclaves of the mainstream professional realms can connect, re-connect, and create partnerships and associations with 'other' others. Such architecture enables the 'mutual recognition and enrichment of each other, rather than 'fetishized community”' (Lévy, 1997: 13). Just as Kornberger and Clegg envision physical space as the 'architectural design of a generative building' which 'offers a way out of power premised on control into more positive power' (2004: 1105), a virtual space can open up the potential for endless and continuing connections.

Nayar (2008) provides an example of such a postcolonial virtual space when he describes the 'Cybermohalla Project', a NGO-run enterprise in India which involves the interaction of common people on the streets through a virtual medium. Local street-users, shopkeepers and other people engage in myriad activities to 'record their responses to events, incidents on the street, conversations in the form of animations, sound, photostories, and text' which are available online (Nayar, 2008). This is a quintessentially hybrid space - a mix of the real and the virtual, with real participants but in virtual interactions.

In the professional world of academe, the open access electronic journal Postcolonial Text is another example of how community feelings are beginning to be articulated in a virtual space. The journal, which showcases work of 'writers who produce their work in relative isolation', seeks to 'provide far greater breadth of research resources to more people ... (and) many libraries (especially in the 'third world') stand to gain far more than they could well imagine as we seek new ways to expand access’ (Mendis, 2004).

It could be argued therefore, that technology, its own power differential notwithstanding, has the potential to ground what Bakhtin (1981) would call a more dialogic, heteroglossic community of scholars - a community that resists dominant assumptions of what a conference or convention is or should be. Indeed, the communicative potential of social networking capabilities built into the 'participatory web' or Web 2.0 technologies such as blogs, digg, Facebook, flickr, Google, MySpace, Ning, podcasting, RSS feeds, SMS, wikis, etc. have opened up spaces between sites and users that allow information to move freely (Web 2.0, 2007). Such an 'architecture of participation' (O’Reilly, 2004; O’Reilly, 2005; Attwell and Elferink, 2007) enables diverse individuals to participate in professional community discussions on their own terms. The concept of an architecture of participation draws on the work of several interdisciplinary scholars on communities of practice 
(most notably Jean Lave and Etienne Wenger (1991) and resonates with the work on distributed communities (see e.g., Cook and Seely-Brown, 1999; Gochenour, 2006). Participation is structured into the very fabric of the technological tools used to generate communities digitally, enabling them to improve with greater use (O'Reilly, 2005). The network effects of these technologies continue to develop participation as individuals pursue their own goals while simultaneously building a collectively valued and valuable outcome for all.

Yet not all the work on distributed communities claims such positive and effective participation. Some scholars' critiques of technological communities claim that technologically mediated interaction limits the ability for participants to establish deeply held cultures (Gergen, 1991; Gergen 2002; Robins and Webster, 1999). For these critics, such spaces develop only superficial or 'banal' cultural practices when there is a lack of face-toface interaction (Robins and Webster, 1999: 239). The central dilemma for Robins and Webster rests on the 'disengagement from the real world and its human condition of embodied (enworlded) experiences and meanings (1999: 244). However, the 'real' world has shifted considerably. So much so, as Hier explains, that 'conceptual coordinates ... such as national statehood, class antagonism, and gainful masculine employment' and the focus on the territorial unit as the 'primary point of reference for questions of economics, politics, and social life' (2008: 31) have been ruptured significantly in the transition from the simple linear logics of the first age of modernity to the second, more reflexive, postmodern age.

As Feenberg and Bakardjieva point out, projects involving online participation 'express situated personal experiences, needs, and problems, and thus undermine the clichéd distinction between "virtual" and "real", (2004: 40). By facilitating conferencing activity over web based or technologically mediated interaction, these new technologies actually create the possibility for a diversity of globally located scholars to convene and confer about social issues of the 'real world.' In creating the COMMUNEcation network, we experienced how Web 2.0 based forms of social networking and conferencing and their accompanying architectures of participation can not only increase the potential for diverse participants to engage in dialogue about common interests, but also enable a more complex, multifaceted, culturally sensitive understanding of social phenomena and provide opportunities to co-construct new patterns and meanings of and for conferencing practices.

\section{Architecting Participation}

Our project set out to re-conceptualize the academic/professional conference as a forum of interactive, ongoing and plural conversations between and among scholars, activists and all those committed to a just, equitable and sustainable world. We felt that this protean form of 'molecular community’ (Lévy, 1997) would enable diverse scholars to 'develop and redevelop projects and resources, continuously refine skills and attempt to enhance individual qualities’(Lévy, 1997: 53). To accomplish such a vision, we had to provide spaces for convergence and divergence, synergy and resistance. We also had to free the communicative practices that underpin conferencing from their geographical, temporal and to some degree, textual constraints.

At first, we considered creating a community alongside traditional conferencing technologies and sought out companies which would enable this process. The search was less than successful and so we began to consider the idea of making the conference entirely online or virtual, given our commitments to geographical diversity, interactive engagement and our desire to be independently funded. We found three exemplars of such conferences. The Online Philosophy conferences (http://experimentalphilosophy.typepad.com/2nd_annual _online_philoso/) and the Crooked Timbers Project (www.crookedtimber.org) use collaborative blogs to communicate and host fortnight-long conferences. The Technology, Colleges and Community (TCC) worldwide online conference (http://tcc.kcc.hawaii.edu/2008/tcc/welcome.html) uses an online community built and hosted through an external commercial party such as Learning Times or Elluminate. Finally, the Internet Engineering Task Force (IETF) uses simple social networking technology such as email listservs and instant messaging to conference. Using diverse practices from each of these conferences and with mentoring from their founders, we began to construct an architecture of participation for COMMUNEcation.

As we reviewed our research and considered how to construct COMMUNEcation, we aspired to create a community with members ranging from activists, philosophers, journalists, sociologists, financial gurus and individual bloggers, all contributing around particular themes. We wanted this community to act as a pool of time and resources for its members, a space where diverse community members could work on cross-national and cultural projects drawing expertise and resources from their global community to engage local issues, a form of Lévy's 'cosmopedia' where 'members could search, inscribe, connect, consult and explore collective discussions, negotiations and developments’ (Lévy, 1997: 217) We had participated virtually in physically located conferences so we knew some of the practices associated therein but we were also influenced by alternative conferencing practices such as that of the Organization, Identity and Location (OIL) conference (http://www.massey.ac.nz/ cprichar/oil.htm) held in Aotearoa New Zealand which has no registration fee and instead asks participants to act as reviewers for submitted works. However, while we knew we could construct 
a space structurally, we could not guarantee inter-action amongst its members. Such a space requires what Rheingold describes as a 'new literacy of cooperation' (2003: 214) and we could not predict all the potential ways in which community members would appropriate, use, transform and reshape the technologies of the community so as to include or exclude, engage or obscure diversity and broaden or curtail dialogue and scholarly understanding of social worlds (Feenberg, 1991; Rheingold, 2003). In the end, we chose to use Ning technology to facilitate such an interaction space as it would provide individual as well as group spaces, the addition of other video, audio, VOIP and organizing tools if we needed, and an email feature as well as updates.

For several months prior to organizing COMMUNEcation, we physically ventured outside of mainstream conferences to engage scholars working on the periphery. Interestingly, while some of these smaller, alternative, conferences deplored the largely Western structures of a dominant profession - the Academy - they often simultaneously upheld them in their own practices. These conferences, however, did give us a chance to connect with networks of scholars in Asia, Latin America, Western and Eastern Europe and Africa. At this time, we were also exposed to the Inter-Asia Cultural Studies Network (http://inter-asia.net/cultural studies school in Asia) which provided an extraordinary exemplar of organizing other-wise. Based on our travels and also our personal networks, we created a list of potential participants and three months prior to its possible start, drafted a call for a virtual conference. By using both personal and professional networks as nodes in larger and more geographically distributed collegial networks, we hoped to spread the word further, as we were aware that most disciplinary listservs are also geographically bound to the more advanced nations. Yet it would be naive to think that these actions did not involve circuits of knowledge and power with such contacts acting simultaneously as potential inclusionary and exclusionary gatekeepers. We asked participants to communicate their intent to participate by early December 2007 and we tried to time the conference to be sensitive to scholars working across the globe, settling finally on 3-5 February 2008. But even this timing was difficult for some participants due to fieldwork as well as family plans in diverse institutional settings which required other compensatory practices of presencing to be adopted at times.

Our open question to guide the conference, asked as inclusively as possible - 'which forms of organizing and communicative practices get discussed' in local contexts? (Nelson-Marsh, Broadfoot, \& Munshi, 2008) as well as our openness to contributions in any form the participant desired e.g. poetry, prose, essay, multimedia etc was designed to be as inclusive as possible in order to open up a cosmopedic space (Lévy, 1997) as far as possible. But in a similar fashion to the gatekeepers mentioned above, the assumption of English as a shared language could also have excluded particular voices from the conversation (Broadfoot et. al, 2008).

Thirty scholars from a variety of disparate and yet inter-linked disciplines, based in locations as diverse as Japan, Nigeria, China, India, the US, Nepal, Aotearoa/New Zealand and Australia, signed up to COMMUNEcation and participated in the virtual conference. Of them, eight submitted specific papers for discussion and for each of the paper contributors, a 'correspondent' was assigned. Considerable time prior to the start of the conference was also spent communicating interaction and conferencing guidelines based on the experiences of the exemplars, and addressing possible difficulties with technology and 'presencing'. Email reminders and handouts were then sent from a dedicated COMMUNEcation email address for participants and this was the only non community based communication technology used and in use.

Contributions were loaded ahead of time to the site for participants to review and participants were then asked to join a discussion group for the 'presenter' at their chosen time for 'presenting'. The multiple technical modalities provided by Ning generally allowed participants to engage in manners with which they felt comfortable but these technological structures could only go so far. Indeed, once these were learned, the communicative practices that ground and support these structures became even more important. For example, to open the conference, one of us recorded a digital video of opening remarks which was loaded just before the first day. Group discussions were also scheduled at an appropriate and convenient time for the contributors in their time zone. Most of the group discussions had about six members each with conversations that moved over the entire three-day conference and extended into the weeks ahead. There were two forums created as well for all participants, including those who did not present specific papers, to reflect on their use of the technology during the conference, overall conference experience, and to discuss themes that were appearing across group discussions. One participant in particular, assumed the role of 'official conference greeter' and posted a welcome and introduction to the community whenever a new member registered.

The amount and frequency of communicative work required to create presence and provide a space for people to participate quickly became apparent as each organizer moderated interactions over three hour periods. Ning with its multiple modalities in terms of blogs, video, discussion etc, enabled most people to find a way to communicate comfortably and in alignment with their own conditions. For three days, the 'conference' as in the arbitrary, artificially bounded arrested practice, ran 24 hours a day. Every night at midnight (US MST), an email 
would be sent outlining the schedule for the following day, reminding participants of new posts, and dealing with any technological issues. When participants were working or not actively conferencing, email alerts were sent from the community updating them on recent activity for them to return to when they could. In this way, absence from any session was countered by later presence with 'presentations' now extending well beyond their allotted time slot. This practice also allowed the discussion to go in multiple directions simultaneously, weaving a much more complex and invigorating conversation as participants probed issues profoundly from their own perspectives and reflected on their own local understandings. The conference 'closed' with a call for papers for publication in a continuing effort to build both sustainability and durability into conferencing practices and the community, recognizing that such efforts are vital to the legitimacy and identity for diverse participants who needed to show their institutions evidence of their 'presence' and 'activity' in international academic spheres. This decision also proved to be nurturing for the relationships formed from profound conversations between diverse and dispersed scholars experiencing their lives academically.

Committed to organizing and working differently as well as expanding the diversity of the realm of academic knowledge and spaces for communication, COMMUNEcation provided a glimpse of how 'online participation offers unique opportunities for actively and interactively pursuing identity-related projects that used to be impossible, even inconceivable' (Feenberg and Bakardjieva, 2004: 40). Unlike the discipline-specific, physically-located conferences that we have been used to attending, this virtual engagement constructed a dynamic form of learning and opened up conceptions of organizing and communicating to a variety of different perspectives. The COMMUNEcation community transformed individual papers and presentations into a mosaic of diverse thoughts, people and experiences around forms of organizing and communicative practices discussed in inter-local contexts (see Broadfoot et. al, 2008b).

\section{Rhizomatic Reflections and Reflexions}

With all the accomplishments of COMMUNECation however, several points of tension remain. Several colleagues, for example, have pointed out that academia requires standards of scholarship and that practices such as peer reviews have their benefits. We agree, but scholars also need to question who determines such standards and practices and how these can act as gate-keeping and 'othering' practices designed to protect the walls of ivory towers. Such standards and standardizing practices are, as King and Frost argue, 'a two-edged sword' and 'it is often forgotten that the fundamental purpose of any standard is to stop innovation' (2002: 22).

COMMUNEcation took a different direction in this regard. We created a 'space in-between' disciplines, nations, institutions and identities; a space and community not bound by time or physical location (Bhabha, 1994, 1996). The organizers and several participants used their positionalities as Western trained and employed, if not born, scholars to facilitate a publication process for diverse colleagues in full recognition of our privilege to do so, aided by the commitments of editors and publishers to increasing diverse scholarship and voices in our discipline. In understanding organizing and communicating in contexts as diverse as Asia, Africa, Oceania, North America, and South America, disciplinary boundaries between public relations, organizational communication, and human resource management were broken down, insights were drawn from community theatre in giving voice to community organization efforts, and lessons were learned about the linguistic differences in communicating organizational experience in diverse locations. COMMUNEcation became 'a place for translation and negotiation, and the disruption and displacement of the largely colonial structures and practices of academic life' (Nelson-Marsh et al., 2008).

Second, when we shared earlier versions of this essay with several of our colleagues who had not participated, they pointed out that there is value in physically spending time, sharing food and drink and having conversations with likeminded scholars. We could not agree more. But what COMMUNEcation has shown us is that those conversations can be started in 'other' spaces and flow into places where participants are co-located. COMMUNEcation the conference, community and its resulting texts, simultaneously challenged and reproduced cultured assumptions and professional norms and rules. We accept these tensions between reproduction and resistance as part of practising postcolonial commitments but also as a reflection of the struggles in which many of our colleagues located outside the center of academe engage every day.

Third, we hoped our commitments to a more equitable and diverse conferencing practices and participants would begin to construct a space characterized by 'borders in motion' (Lévy, 1997: 217). We wouldn’t want to describe COMMUNEcation as a tight-knit, closely-bound community. Like most virtual communities which 'give rise to specialized relationships, not all-embracing solidarities' (Feenberg and Bakardjieva 2006: 39), it strengthened bonds between cross-continental strangers but didn't lead to community manifestos. As a molecular community (Lévy, 1997), COMMUNEcation reorganized itself in real time with each individual act 
of its participants. As organizers we assumed in a postcolonial fashion that all participants had meaningful and valid forms of knowledge to share about communicating and organizing practices in their locale. There were tremendous learning opportunities to be found in this pilot attempt at a more diverse, equitable and ethical conferencing experience.

Yet, it would be difficult to say that the conference avoided exclusionary practices completely. The ways in which the call was sent out to personal and professional networks delimited participants as did the timing of the conference. Indeed, as we fleshed out the construction of COMMUNEcation, we found it was difficult to meet all demands optimally despite our commitments to achieve the best for all. As with most organizing forms, we were forced to satisfy, instead of optimize. With all these points in mind however, the rhizomatic action and effect of individual and collective networks brought people into lives and work that provided 'rooms with views' on the nature of organizing and communicating in the global context we might never see or hear at mainstream conferences. 'Friends' met through COMMUNEcation reconnected a few months later at physically co-located conferences. Perspectives were more clearly understood, commitments more cemented.

Architecting and accomplishing participation however, has not been without struggle or considerable learning for us as scholars trained and to some extent based in the Global North with commitments to our colleagues in and of the Global South. Technology, even with its capability to bend space and time, is still dependent on access, and as we have discussed, some participants had to go to extraordinary lengths to find a stable internet connection, some travelling miles to the nearest city, one engaging in the security of multiple computers and another needing a permission letter written to their institution for an armed guard to escort them to another location with a stable network. These were indeed, extraordinary commitments to participation that members of COMMUNEcation neither foresaw nor entirely expected.

Fourth, the beauty of ongoing conversations and sustaining them through the Web 2.0 tools attached to Ning as well as advance sharing of contributions as pieces of this architecture also revealed a flaw in our assumptions around the critical nature of time. COMMUNEcation used specific presentation times as a conferencing practice to provide a familiar conferencing format in which individuals could participate but it quickly became apparent that the combination of who people are, what technology is and does, and the meanings constructed for technological friends disrupt that bounded practice completely. The simultaneous collapsing and extension of time experienced by participants especially, questioned the need for a three-day structure (another practice brought into the frame to legitimate the conference and community to external eyes). The Philosophy and Education conferences that we had reviewed as exemplars extend their conferences over weeks and when we asked community members, they too iterated that because technology made our conversations durable and sustainable by recording them as texts, it would also be possible to have more far reaching discussions with one or two 'presentations' or fora held over a week.

As all these reflections indicate, online conferencing allows participation to grow organically. This is in sharp contrast to physical conferencing where time and space are constrained by other uses. Experience with the COMMUNEcation community indicates that participation takes a lot of time and a lot of room to grow. Participation was the one thing organizers could neither control nor guarantee, resting entirely in the individual actions of COMMUNEcation members. Veterans of online groups and communities know well the existence of lurkers and spectators, and there were definitely some participants more active than others. Yet, as in face- toface interaction, this does not necessarily mean that participation or engagement was not occurring. Documents and discussions were read, pages created, relationships formed, maybe not in the moment, but over time. The 'community' itself waxed and waned in nature and its activity as its members engaged in various forms of work. At the time of writing it is quiet, after a period of activity around writing, but will soon become more active as we begin to 'plan' our next 'gathering' and texts and conversations travel to other venues, moving into the focus of other scholarly eyes and lives.

\section{Conclusions}

In this essay we have argued that online or virtual conferencing may provide an alternative organizing structure that can open up potential for 'rhizomatic multiplicities' (Deleuze \& Guattari, 2004: 37). COMMUNEcation, as a pilot experience, has shown that even a small number of contributors can take conversations central to their professional experiences to different destinations and in so doing, begin to transform what we know and how we are, as scholars. Using participatory technological tools shakes up old notions of time, space, and text to create fresh and more equitable virtual platforms of scholarly exchange. In the frequency and constancy of communicative practices of conferencing we begin to rebuild and restructure diverse forms of professional community and organizing towards hybrid forms of existence that blur the boundaries of nations, ethnicities, scholarship, and disciplines. 
Participatory technologies such as those of Web 2.0 and the connections they facilitate move us away from a colonialist mindset of bounded identity, community, and cultural construction and allow us to re-imagine what it means to be a scholar, to be part of a scholarly community and culture, and to participate in co-creating the rites of academic conferencing. Community and conferencing practices such as those that underpin COMMUNEcation enabled the space to be something more than just informational, a momentary snapshot of scholarly activity bounded in space and time. Instead, these practices highlighted the architecture of deterritorialization and the accompanying communicative work necessary to prioritize collective interaction and knowledge above the demonstration of individual expertise. They also highlighted the contested, partial and fragmented nature of knowledge and the ongoing construction of the same as it met practices within the community while lodged externally in the local contexts of participants. Living knowledge, as a product of interaction with others, depends upon the construction of social bonds (Lévy, 1997). COMMUNEcation has demonstrated that these social bonds and the participation that emerges through them, take time - much longer than the structures of traditional conferencing allow. To construct collective intelligence, there needs to be time to listen, express, decide, evaluate, organize, connect and envision (Lévy, 1997). While difficult to construct within the constrictive structures of traditional conferencing practices, the presence of participatory technologies alone is also not enough to engender an exchange of knowledge and the creation of social bonds. It is the sociability performed through individual actions in collaboration with these technologies that begins to weave a dynamic, deterritorialized space capable of integrating forms of being, knowing and doing across diverse spatial and temporal dimensions. The ways in which we come to know lead us back to who we are and who we are in interaction with each other.

In conclusion, participation drives a collective but it can never be assured. As Web 2.0 tools abound across professional contexts, it is important to remember that while on the surface they may be easy to grasp, their full potential lies in the ways in which we begin to engage their multivalent potentialities across diverse contexts. These multivalent potentialities are also highly gendered, cultured and classed creations of their masters and they have an 'ideal user/partner' in mind. Therefore, if the goal is to make conferencing more ethical, equitable, and participatory for diverse populations, the technological tools deployed must demonstrate requisite variety. One tool does not fit all situations as we discovered with COMMUNEcation when one member wanted to present using Adobe Connect. Thus, one of the continuing questions for online conferencing will remain with continuous tool development that begins to engage in reciprocal relationship with its user/partner. Engaged participation is the holy grail of the social media industry, but as always, the answer lies with people. It is in our experimentations with these tools and our extension of reach outside of our 'local' academic contexts, that we begin to reassign symbolic meaning to 'other-wise' ways of being and working with each other.

\section{Acknowledgements}

We acknowledge the members of the COMMUNEcation network for their participation in our voyage of discovery. We also acknowledge the feedback and helpful comments on earlier drafts of this article from the editors and reviewers of this journal and also members of the Management Communication research syndicate at the University of Waikato. 


\section{References}

Attwell, G. and R. Elferink (2007) ‘Developing an Architecture of Participation’, Paper for ICL Conference. URL (consulted June 16, 2009):

http://project.bazaar.org/wpcontent/stall_project_uploads//2007/09/111_final_paper.pdf.

Bagchi, A.K. , D. Sinhaand B. Bagchi (2005) 'Introduction’, in A. K. Bagchi, D. Sinha and B. Bagchi (eds.) Webs of History, pp. 9-22. New Delhi: Manohar Publishers.

Bakhtin, M. (1981) The Dialogic Imagination: Four Essays M. Holquist (ed.). Translated by C. Emerson and M. Holquist. Austin, TX: University of Texas Press.

Beck, U. and C. Lau (2005) 'Second Modernity as a Research Agenda: Theoretical and Empirical Explorations in the "Meta-Change" of Modern Society', British Journal of Sociology 56(4): 525-58.

Bhabha, H.K. (1994) The Location of Culture. London: Routledge.

Bhabha, H. K. (1996) ‘Culture’s In-Between’, in S. Hall and P. du Gay (eds.) Questions of Cultural Identity, pp.53-60. London: Sage Publications.

Bowker, G.C. and S.L. Star (1999) Sorting Things Out: Classification and its Consequences. Cambridge, MA: MIT Press.

Broadfoot, K. J., \& Munshi, D. (2007) Diverse voices and alternative rationalities: Imagining forms of postcolonial organizational communication, Management Communication Quarterly 21(2): 249-267.

Broadfoot, K., Cockburn, T., Cockburn-Wootten, C., do Carmo Reis, M., Gautam, D., Malshe, A., Munshi, D., Nelson-Marsh, N., Okwori, J., Simpson, M., \& Srinivas, N. (2008). A Mosaic of visions, daydreams and memories: Diverse inlays of organizing and communicating from around the globe, Management Communication Quarterly 22 (2): 322-350. 
Cook, S.D.N. and J. Seely Brown (1999) 'Bridging Epistemologies: The Generative Dance between

Organizational Knowledge and Organizational Knowing’, Organization Science 10 (4): 381-400.

Deleuze, G. and F. Guattari (2004) A Thousand Plateaus: Capitalism and Schizophrenia. Translated by B.

MasSumi. London: Continuum

Feenberg, A. (1991) Critical Theory of Technology. New York: Oxford University Press.

Feenberg, A. and M. Bakardjieva (2004) ‘Virtual Community: No “Killer Implication”', New Media and Society $6(1): 37-43$.

Flew, T. (2005) New Media: An Introduction. Melbourne, Australia: Oxford University Press.

Gajjala, R. and A. Mamidipuni (2002) 'Gendering Processes within TechnologicalEnvironments: A

Cyberfeminist Issue’, Rhizomes, 4, (Spring), URL (consulted June 12, 2007):

http://www.rhizomes.net/issue 4/gajjala.html

Gergen, K. (1991) The Saturated Self: Dilemmas of Identity in Contemporary Life. NewYork, NY: Basic Books.

Gergen, K. (2002) 'The Challenge of Absent Presence’in J.E. Katz and M.A. Aakhus (eds.) Perpetual Contact:

Mobile Communication, Private Talk, Public Performance, pp.227-241. Cambridge, MA: Cambridge University Press.

Gochenour, P. H. (2006) 'Distributed Communities and Nodal Subjects’, New Media and Society 8 (1): 33-51.

Green, L. (2001) 'Technoculture: Another Term that Means Nothing and Gets Us Nowhere?’, Media

International Australia 98: 11-26.

Hier, S. (2008) 'Transformative Democracy in the Age of Second Modernity: Cosmopolitanization, Communicative Agency, and the Reflexive Subject', New Media and Society 10 (1): 27-44.

Kornberger, M. and S. R. Clegg (2004) 'Bringing Space Back In: Organizing the Generative Building', 
Organization Studies 25: 1095-1114.

Kreiner, K. and M. Schultz (1995) ‘Soft Cultures: The Symbolism of Cross-Border Organizing’, Studies in Culture, Organization and Societies 1: 6383.Lash, S. (2003) 'Reflexivity as Non-Linear', Theory, Culture and Society 20(2): 49-57.

Lave, J. and E. Wenger (1991) Situated Learning: Legitimate Peripheral Participation. Cambridge: Cambridge University Press.

Lévy, P. (1997) Collective Intelligence: Mankind's Emerging World in Cyberspace. Translated by R. Bononno. Cambridge, MA: Perseus Books.

Markley, R. (1996) Virtual Realities and Their Discontents. Baltimore: Johns Hopkins University Press.

McKibben, B. (2003) Enough: Staying Human in an Engineered Age. New York: Times Books/Henry Holt.

Mendis, R. (2007) 'Welcome to Postcolonial Text’, Postcolonial Text, 1, URL (consulted June 12, 2007) http://postcolonial.org/index.php/pct/article/viewArticle/361/127

Munshi, D., Kurian, P., Bartlett, R.V., \& Lakhtakia, A. (2007) A map of the nanoworld: Sizing up the science, politics, and business of the infinitesimal. Futures 39: 432-452.

Nayar, P. (2008) 'New Media, Digitextuality, and Public Space: Reading “Cybermohalla”, Postcolonial Text 4 (1): $2-12$

Nelson-Marsh, N. (2007) Reconsidering the conceptual relationship between organizations and technology: A study of the Internet Engineering Task Force as a virtual organization. Unpublished doctoral dissertation. University of Colorado.

Nelson-Marsh, N., Broadfoot, K. J., \& Munshi, D. (2008). COMMUNEcating in the spaces in-between: Creating new understandings of organizing and communicative practice around the globe. Management Communication Quarterly, in press, 22. 
Noronha, F. (2006) ‘Can Open Access Offer Science Where No One is Left Behind?’, The Communication

Initiative, 2006. URL (consulted June, 12 2007): http://www.comminit.com/trends/ctrends2006/trends$\underline{314 . h t m l}$

O’Reilly, T. (2004) ‘Open Source Paradigm Shift’. O’Reilly. URL (consulted June, 12 2009):

Mediahttp://www.oreillynet.com/pub/a/oreilly/tim/articles/paradigmshift_0504.html

O’Reilly, T. (2005) 'What is Web 2.0? O’Reilly. URL. (consulted July 17, 2009):

http://oreilly.com/1pt/a/6228.

Poster, M. (1995) The Second Media Age. London: Blackwell.

Rheingold, H. (2003) Smart Mobs. Cambridge, MA: Perseus Publishing.

Robins, K. and F. Webster, (1999) Times of Technoculture: From the Information Society to the Virtual Life. New York: NY: Routledge.

Simpson, M. (2008). Section in Broadfoot, K., Cockburn, T., Cockburn-Wootten, C., do Carmo Reis, M., Gautam, D., Malshe, A., Munshi, D., Nelson-Marsh, N., Okwori, J., Simpson, M., \& Srinivas, N. (2008). A Mosaic of visions, daydreams and memories: Diverse inlays of organizing and communicating from around the globe, Management Communication Quarterly 22 (2): 322-350.

Shohat, E. and R. Stam (1996) Unthinking Eurocentrism: Multiculturalism and the Media. London: Routledge.

Shome, R. (1996) 'Postcolonial Interventions in the Rhetorical Canon: An “Other” View', Communication Theory, 6: 40-59.

Web 2.0. (2007) Wikipedia, URL (consulted June 4, 2007): http://en.wikipedia.org/wiki/Web_2.0.

Weick, K. (1995) Sensemaking in Organizations. Thousand Oaks, CA: Sage.

Wenger, E. (1999) Communities of Practice: Learning, Meaning, and Identity. Cambridge: Cambridge University Press. 